NBER WORKING PAPERS SERIES

INVENTION AND BOUNDED LEARNING BY DOING

Alwyn Young

Working Paper No. 3712

NATIONAL BUREAU OF ECONOMIC RESEARCH

1050 Massachusetts Avenue

Cambridge, MA 02138

May 1991

I am grateful for the helpful comments of Roland Benabou, Olivier Blanchard, Lael Brainard, Julio Rotemberg, and the participants at the NBER's Fall 1990 Growth Conference. Naturally, all remaining errors are my own. This paper is part of NBER's research program in Growth. Any opinions expressed are those of the author and not those of the National Bureau of Economic Research. 
NBER Working Paper \#3712

May 1991

\title{
INVENTION AND BOUNDED LEARNING BY DOING
}

\section{ABSTRACT}

This paper presents a model of the interaction between invention and learning by doing. Learning depends upon invention in that learning by doing is viewed as the serendipitous exploration of the finite productive potential of invented technologies. At the same time, the profitability of costly invention is dependent upon learning in that costs of production depend upon the society's aggregate historical learning experience. The resulting model is a true hybrid. With small markets, the profitability of invention is low, and hence the rate of invention becomes the constraining factor in growth. With large markets, invention is very profitable and tends to pull ahead of the society's learning experience. The consequent growing gap between the technological frontier and the society's industrial maturity squeezes returns, leading to an equilibrium in which the rate of invention (and growth) is paced by the society's rate of learning.

\author{
Alwyn Young \\ Sloan School of \\ Management \\ M.I.T. \\ Cambridge, MA 02139
}




\section{INTRODUCTION}

Models of endogenous technical change fall into two broad, and yet surprisingly disjoint, categories. On tlie one hand, there are nodels of "invention" (e.g. Grossman and Helpman 1989, Romer 1990, Segerstrom et al. 1990), which view technical change as a costly and deliberative process. On the other hand, there are nodels of "learning by doing" (e.g. Arrow 1962, Lucas 1988), which view technical change as the serendipitous outcome of goods production. Models of invention generally focus on factors which influence the incentive to consciously innovate, such as the institutional frainework and market size, ${ }^{1}$ whereas models of learning focus on factors which influence the incentives to produce different types of goods, such as the pattern of comparative advantage. ${ }^{2}$ This paper attempts to integrate these two literatures, developing a model in which sustained technical progress involves an interaction between conscious decisions (invention) and serendipitous outcomes (leaming). This provides some preliminary insights into the conditions under which either the incentives to innovate or the pattern of demand and production are the binding constraints on growth.

Almost all leaming by doing growth models assume that the potential productivity gains from learning by doing are essentially unbounded. ${ }^{3}$ Careful reflection suggests, however, that

\footnotetext{
'See, for examples, Grossman and Helpman (1990), Rivera-Batiz and Romer (1989) and Segerstrom et al (1990).

${ }^{2}$ See Bardhan 1970, Lucas 1988, and Young 1991.

${ }^{3}$ The usual formulation involves a finite number of goods, with productivity in each industry either a linear (c.g. Lucas 1988) or a log-linear (e.g. Arrow 1962, Bardhan 1970, Krugman 1987) function of cuinulative production or investment experience, both of which imply that experience alone can lead to unbounded productivity improvements. Young (1991) introduces a bound on learning in each good, allowing for unbounded growth by taking as given the existence of an infinite continuum of potentially producible goods. Bounds on learning have frequently been introduced in partial equilibrium analyses, as in Fudenberg and Tirole (1983), Spence (1981) and Stokey (1986).
} 
the potential for learning in the production of any particular good, using any particular process, is in fact finite and bounded. When a new technical process is first invented, rapid leaming occurs as, by virtue of experience, the productive potential of that process is explored. After some time, however, the inherent (physical) limit on the productivity of a technology will be approached and learning will slow, and perhaps ultimately stop. In the absence of the introduction of new technical processes, it is unlikely that learning by doing can be sustainer. This would explain why, despite considerable economic activity, learning by doing did not lead to sustained economic growth prior to the modern era. ${ }^{4}$

The dependence of sustained learring on a continued supply of new inventions does not necessarily detract from the importance of modelling the learning process itself. To begin with, empirical evidence suggests that the actualization of the productive potential of new technologies (learning) may actually lead to productivity increases several orders of magnitude greater than those associated with the original innovations themselves. Furthennore, the dynamics induced

\footnotetext{
${ }^{4}$ Most of the empirical work on learning by doing (e.g. Wright 1936, Hirsch 1956, Alchian 1963, and Lieberman 1984) has focused on the log-linear model, where, typically, the cost of production of the nth unit is equal to a constant times cumulative output up to the nth unit raised to a negative power (the progress elasicity), i.e. $C_{n}=A E_{n}^{-b}$. This formulation clearly allows for unbounded learning. Many of the early empirical studies of leaming (c.g. Carr 1946, Asher 1956. Conway and Schultz 1959 and Baloff 1966) argued that learning was fundamentally bounded. Although there has been no attempt to formally test whether learning is bounded or unbounded, it is interesting to note that Levhuri and Sheshinski (1973) did find that a formulation in which the elasticity of output with respect to experience was a decreasing function of the level of experience provided as good a fit as the usual log-linear model.

${ }^{5}$ Thus, Enos (1958) found that whereas during the initial introduction of new petroleum refining processes cost reductions of $1.5 \%$ per annum were achieved, subsequent improvements of these same processes led to cost reductions of $4.5 \%$ per annum. Similarly, Mak and Walton (1972) found that although the initial introduction of the steamboat, between 1815 and 1820 , to western inland rivers led to a signficant decline in freight costs, subsequent improvements in the steamboat, principally incremental changes in hull design, led to much greater declines in shipping costs between 1820 and 1860 . For example, on the Louisville-New Orleans route upstream rates per $100 \mathrm{lbs}$. fell from $\$ 5.00$ in 1815 to $\$ 2.00$ in 1820 to $\$ 0.25$ in $1860(\$ 3.12$ to $\$ 2.00$ to $\$ 0.28$ in constant 1820 dollars).
} 
by leaming, even if subsidiary to the process of invention, might, in particular problems, be of interest. Most importantly, from the point of view of the theorist, is the fact that learning by doing might have important feedbacks into the inventive process; perhaps by influencing both the costs of invention and post-invention costs of production. In this paper I focus, in the main, on the latter mechanism.

Clearly, a product's own production experience, combined with any benefits (i.e. technical spillovers) it receives from learning by doing in other industries, will influence the time path of that product's production costs after it's invention. Furthermore, if one believes that there are significant technical spillovers across industries, ${ }^{6}$ then it follows that aggregate social learning should also influence a product's initial costs of production at the moment of invention. How costly it is to produce a new product is at least partly dependent upon how much experience a society has in producing similar products. By influencing both the initial and subsequent costs of production of new inventions, learning by doing determines the profitability, and hence the rate, of invention. Thus, just as sustained learning is dependent upon invention, so sustained invention might be dependent upon learning. The model of this paper attempts to capture this dynamic interaction.

To outline the model, I begin by positing a society which at any point in time knows how to produce a fixed set of goods. Each of these goods experiences bounded learning by doing. The knowledge so generated is non-appropriable by firms and spills over across sectors, with, for example, the knowledge acquired by a firm in industry A funding applications in industries $B$ and C. Entrepreneurs invent new goods, receiving an infinitely lived patent as compensation for their

\footnotetext{
${ }^{6}$ Rosenberg (1982) documents numerous historical examples of technical spillovers across sectors, while Jaffe (1986) fuds econometric evidence of R\&D spillovers across technically similar industries.
} 
efforts, and there is free entry into the process of invention. Thus, despite the perfect spillovers of (learnt) knowledge across sectors, final goods production takes place under conditions of monopolistic competition.

To close the model. I introduce a specification for preferences in which no good is essential, but in which, for any given distribution of prices, demand is unitary income elastic. The fact that no good is essential allows the model to incorporate a rich narrative structure, capturing both the qualitative and the quantitative dinnensions of growth. Over time, the society will produce a changing basket of goods, with new goods replacing old obsolete goods and with the quantities consumed, of the new substitutes, rising. For their part, the unitary income elasticities make the analysis of intertemporal consumption smoothing quite tractable. In sum, the model of this paper encompasses invention, bounded learning by doing with spillovers across goods, old goods obsolescence, and non-trivial intertemporal decision-making.

As we shall see, the model behaves like a true hybrid. With small markets, the profitability of invention is low, and hence the rate of invention becomes the constraining factor in growth, with the parameter goveming the rate of learning having no effect. With large markets, invention is very profitable and and tends to pull ahead of the society's learning experience. Since profits depend upon production costs which in turn depend upon social learning, this growing gap between the technological frontier and the society's industrial maturity squeezes returns, leading to an equilibrium with the rate of invention (and growth) paced by the society's rate of learning. There exist equilibria in which the process of invention becomes largely irrelevant, in the sense that a subsidy to invention would have no effect on the economy's steady state growth rate.

Section II presents the basic structure of the model. Section III discusses some of the critical assumptions. Sections IV and V develop the instantaneous and intertemporal aspects of the 
general equilibrium. Section VI analyzes the steady state and section VII concludes. 


\section{A MODEL OF INVENTION AND LEARNING}

Imagine that all of the goods that have ever been or ever will be invented can be arranged, in order of increasing technical sophistication, along the real line. At any point in time, however, a society will only know how to produce a subset of this real line, goods in $[0, N(t)]$, where $N(t)$ naturally denotes the most sophisticated good the society is currently able to produce. ' Labour is the sole factor of production, and the function a(s,t) describes the amount of labour necessary to produce one unit of good $s$ at time $t^{8}{ }^{8}$ This economy experiences bounded learning by doing with spillovers across goods. Thus, the unit labour requirements function is given by:

(1) $a(s, t)=\bar{a} e^{-s} \forall s \in[0, T(t)] \quad a(s, t)=\vec{a} e^{-T(t)} e^{s-T(t)} \forall s \in[T(t), N(t)]$ with $T(t)$ evolving according to the learning by doing equation:

(2) $\dot{T}(t)=\int_{T(r)}^{N(r)} \psi L(s, t) d s$ where $\psi$ denotes the rate at which each worker leams.

Equations (1) and (2) are a specific functional form of a more general learning by doing technology outlined in Young (1991). Leaming is bounded in that the amount of labour required to produce good $s, a(s, t)$, cannot fall below $\bar{a} e^{-s}$. Since all goods enter symmetrically into utility (see below), the fact that this lower bound is downward sloping reflects the notion that the ultimate productivity of labour (in units of utility) is increasing in the technical sophistication of the

${ }^{7}$ Throughout this paper, the notation with respect with time denotes an implicit, rather than explicit, dependence that emerges from the general equilibrium behavior of the various economic actors. Superscripted dots will denote time derivatives.

${ }^{8} \mathrm{a}(\mathrm{s}, \mathrm{t})$ is defined only on the domain $[0, \mathrm{~N}(\mathrm{t})]$. 
production processes involved. ${ }^{9}$ There are spillovers in learning across goods, with technical improvements originating in any particular industry s having applications in other industries. This is encompassed in the formulation for $T(t)$, which essentially implies that these spillovers are symmetric across all sectors. ${ }^{10}$ Once an industry has reached its lower bound, $\bar{a} e^{-\gamma}$, there is nothing left to learn in that industry, and thus further experience in the production of that good cannot contribute to productivity increases in the rest of the economy. Hence, the economy-wide learning by doing equation (2) only includes the labour devoted to the production of goods in which learning has yet to be exhausted." Given the symmetrical nature of learning by doing spillovers, learning is exhausted sequentially in goods and $T(t)$, the most recent good to reach the lower bound $\bar{a} e^{-s}$, constitutes a state variable which summarizes the society's cumulative leaming experience. ${ }^{12}$

New goods are invented through the creative efforts of entrepreneurs/firms, who acquire an

${ }^{9}$ One could, equivalently, scale units so that the lower bound on unit labour requirements is increasing in s, but with higher numbered goods providing greater utility per unit. A practical example might be the replacement of the plonograph by the compact disc player. Although compact disc players are more expensive than phonographs, they provide greater utility per unit cost, and hence are replacing the older system.

${ }^{10}$ Equation (2) also implies that the contribution of an industry's own output to improvements in its productivity is of zero measure relative to the effect of learning spillovers from other sectors. Complicating the model to allow for own industry effects that are of positive measure relative to economy-wide spillovers would not, I believe, significantly change the results highlighted in this paper.

${ }^{11}$ Thus, as in the typical learning by doing model, there is a constant rate of learning, $\psi$, but only until such time as the industry has exhausted its potential stock of knowledge. same $T(t)$.

${ }^{12}$ As can be seen from (2), many different historical production paths could lead to the 
infinitely lived patent on each good they invent. The rate of invention is linear in the aggregate amount of labour devoted to research:

(3) $\dot{N}(t)=L_{R} / a_{R}$

and there is free entry into the inventive process. Firms finance their R\&D efforts by selling shares, which are traded in a capital market. After a good is invented, the firm owning the patent will engage in monopolistic competition with all other patent holders, distributing any profits to its shareholders. ${ }^{13}$

In this economy there are $\mathrm{L}$ representative consumers, each of whom inelastically supplies one unit of labour at all times $t$ and seeks to maximize the present discounted value of the logarithm of a time separable utility functional:

(4) $\operatorname{Max} T=\int_{1}^{-} e^{-\alpha(v-t)} \log (U\{C(., v)\}) d v$

subject to the intertemporal budget constraint:

(5) $\int_{1}^{\infty} e^{-R(v)+R(t)} E(v) d v=A(l)+\int_{1}^{\infty} e^{-R(v)+R(t)} w(v) d v$

where $R(t)$ denotes the cumulative interest factor up to time $t$ and $w(t)$ and $A(t)$ denote the nominal wage and individual assets at time $t$. $E(t)$, instantaneous consumer expenditure, equals:

(6) $E(t)=\int_{0}^{N(t)} p(s, t) C(s, t) d s$

${ }^{13}$ Equation (3) does not allow for any feedback from the process of leaming into the actual costs of invention. This could easily be modified, say by making $\dot{N}(t)=l(N(t)-T(t)) L_{R} / a_{R}$, with $l^{\prime}()<0,. l(0)=1$. This formulation would posit that the costs of further innovation are lower the more fully a society has explored its existing technical capabilities. As it adds additional complexity, without changing the results in any meaningful way, I do not incorporate this notion into the model. 
with $p(., t)$ and $C(., t)$ describing goods prices and individual consumption along $[0, N(t)]$. The utility functional, $\mathrm{U}\{\mathrm{C}(., \mathrm{t})\}$, is given by: $:^{14}$

(7) $U\{C(., t)\}=\int_{0}^{N(t)}\|C(t)\| g\left(\frac{C(s, t)}{\|C(t)\|}\right) d s$

where:

(8). $\|C(t)\|=\int_{0}^{N(t)} C(s, t) d s$

and where $g($.$) is strictly concave and continuously differentiable, with:$

(9) $g(0)=0, g^{\prime}(0)<\infty$

For the purposes of this paper, it is necessary to pick a particular functional form for $\mathrm{g}($.$) , and to$ that end I choose the quadratic: ${ }^{\text {is }}$

(10) $g(x)=x-\frac{x^{2}}{2}$

Clearly, the presence of $\|C(t)\|$ in $g($.$) ensures that, for any given p(., t)$ function, consumer

${ }^{14}$ Preferences are actually defined over all current and future goods along the real line, $[0, \infty)$. Since at any point in time $t$, consumption of any $\operatorname{good} x>N(t)$, which has yet to be invented, is trivially zero, for ease of exposition I restrict the upper bound on the integral to $N(t)$.

${ }^{15}$ None of the results of this paper are dependent upon the choice of the quadratic functional form, which simply eases the analysis. Since $g($.$) embodies the consumer's desire for vari-$ ety, the quadratic implies that the consumer could derive disutility from concentrating consumption on a small set of goods. Examples readily come to mind. Imagine that all of one's nutritional needs are satisfied and that only the varieties of food one will consume remain to be chosen. Clearly, if one were forced to eat only one kind of food for each and every meal, one would soon derive considerable disutility from the actual act of consuming that food. 
demand for each good $s$ is unit income elastic. ${ }^{16}$ At the same time, the concavity of $g($.$) ,$ combined with the restriction on $g^{\prime}(0)$, indicates a strong, but not unbounded, preference for variety. Changes in $\mathrm{p}(., \mathrm{t})$ will lead to changes in the set of goods consumed, with, over time, new and more advanced goods replacing older more primitive goods. Thus, these preferences retain a rich structure, whilst remaining tractable enough to handle non-trivial intertemporal optimization."

${ }^{16}$ One can see that if one multiplies the consumption of each good $s$ by a constant $\lambda$, the marginal utilities $(g)$ do not change. The notion of these type of preferences is borrowed from Wan (1975), who, however, does not seem to have considered the fact that the consumer must take into account the effect of $C(s, t)$ on $\|C\|$ in picking an optimal consumption basket (see appendix 1 further below).

${ }^{17}$ For examples of similar types of preferences without unitary income elasticities, see Stokey (1988 and 1990) and Young (1991). Despite the non-unitary income elasticities, Stokey (1990) handily solves the consumer's intertemporal maximization problem in the steady state. 


\section{DISCUSSION OF THE MODEL}

Readers familiar with models of endogenous growth based upon innovation, e.g. Romer 1990 and Grossman and Helpman 1990, are probably aware that the usual formulation for the rate of invention is of the form: $\dot{N}(t)=N(t) L_{R} / a_{R}$. This implies powerful spillovers in knowledge, with the absolute productivity of inventors rising in the society's degree of development. Although this assumption may or may not be empirically valid, it is important to recognize the technical role it plays in those models. Without old goods obsolescence, the potential profitability of new inventions is inversely related to the existing number of competitive products. To sustain steady state innovation, it is necessary to have the cost of innovation inversely related to the existing number of products as well. With old goods obsolescence, as will occur in the model of this paper, the existing number of obsolete products, such as oil lamps and rickshaws, is not relevant to determining the profitability of the next invention. Thus, I can specify a somewhat weaker form of spillovers. Although patents protect innovators from immitative production, they do not prevent other entrepreneurs from examining new products and learning their technical qualities. Using this information, entrepreneurs are able to invent the next generation of improved products $(N(t)+\varepsilon)$, which have, ultimately, greater productive potential, as given by the lower bound on unit labour requirements, $\bar{a} e^{-s} .18$

From the above, it should be apparent that the distinction between learning and invention is not that the former involves technical spillovers, whilst the latter does not. In the model of this paper, both activities create positive externalities which are not captured by those responsible for generating the new knowledge. The crucial distinction is that learning generates knowledge as a

${ }^{18}$ In this respect, the model is quite similar to the quality ladders models of Grossman and Helpman (1989) and Segersurom, Anant and Dinopoulos (1990) in which each new generation of products involves a constant percentage improvement in quality over the previous generation, with the cost of invention unaffected by the existing number of inventions. 
costless by-product of other activities, whereas invention involves costly investigation.

Although the technologies generated by learning by doing might be appropriable and could give rise to conscious attempts to move down leaming curves, ${ }^{19}$ this is not a necessary condition for technical change to occur in a learning model. Whether or not the benefits are appropriable, serendipitous learning by doing will give rise to sustained technical progress. In contrast, given that it is costly, at least some of the benefits of invention must be directly appropriable by the inventor for technical progress to occur. Table I below summarizes these distinctions.

\footnotetext{
${ }^{19}$ As in Spence 1981.
} 


\begin{tabular}{|l|c|c|}
\hline \multicolumn{3}{|c|}{ TABLE I: DISTINCTIONS } \\
\hline & Learning by Doing & Invention \\
\hline Costly: & No & Yes \\
\hline Spillovers: & Yes & Yes \\
\hline Appropriable: & No, but could be. & Yes, and must be. \\
\hline
\end{tabular}

In this paper I assume that the benefits of leaming are non-appropriable, whereas inventive activity is compensated with the award of infinitely lived patents. From these assumptions follow the principal results of the model. When inarkets are small, the effective compensation given to inventors is too small and the economy stagnates, as invention becomes the constraining factor in growth. A small subsidy to invention would improve social welfare. When markets are large, the infinitely lived patent provides an excessively large reward to inventive activity. Invention races ahead of the society's current rate of learning, and growth becomes constrained, and paced, by the rate of learning. In this case, a tax on invention, releasing resources for production, would actually improve social welfare. In a model in which two activities are necessary for growth, but only one is compensated, there can easily be excessive activity in the compensated sector, even though that sector generates positive externalities. 


\section{INSTANTANEOUS EQUILIBRIUM}

I begin with the analysis of the instantaneous equilibrium at each time $t$. Let $w(t)$, the nominal wage, be the numeraire. Thus, the flow of each consumer's labour income equals 1 and all prices and values are denominated in units of labour. To simplify the notation, in what follows I shall frequently suppress the notation denoting the implicit dependence of the variables on time.

Given the time separability of the consumer's utility function, the consumer's optimal consumption and expenditure programme can be broken down into a two stage analysis: first maximizing instantaneous utility subject to instantaneous expenditure, and then, with $U(C(., t))$ defined as a function of $E(t)$ and $p(., t)$, maximizing total intertemporal utility subject to the intertemporal budget constraint. With respect to the maximization of the instantaneous utility functional, $\mathrm{U}\{\mathrm{C}()$.$\} , the solution to this problem is best understood by characterizing C(s) /\|C\|$ as a consumption density $f(s)$, which integrates to 1 . The consumers problem is to allocate this consumption density across goods and then adjust the consumption scaling factor $(\|C\|)$ based upon the desired level of instantaneous expenditure, i.e.:

(11) $\operatorname{Max} U\{C(., t)\}=\int_{0}^{N(r)}\|C(t)\| g(f(s)) d s$ subject to:

(12) $1=\int_{0}^{N} f(s) d s$

(13) $E=\int_{0}^{N} p(s) f(s)\|C\| d s$

Since all goods enter symmetrically into her utility, the consumer will naturally choose to consume the cheapest goods. If the consumer consumes any good $z$, she will consume all goods 
$s$ cheaper than $z$. Given that the consumer has a bounded desire for variety, it follows ${ }^{20}$ that there exists some limit good $\mathrm{Z}$ such that the consumer consumes all goods which are cheaper than $\mathrm{Z}$, and consumes no goods which are more expensive than $Z$. The density of consumption allocated to each good $s$ (cheaper than $Z$ ) should, intuitively, depend in some fashion on the difference between the price of good $\mathrm{Z}$ and the price of good $\mathrm{s}$. As it so happens, with quadratic utility this dependence is linear, with the optimal $\mathbf{f}(\mathbf{s})$ being given by: $:^{2 !}$

(14) $f(s)=\lambda[p(Z)-p(s)]$

where $\lambda$ is the marginal utility derived from an additional unit of expenditure, $E$, at the consumer optimum. Good $\mathrm{Z}$ is determined by the requirement that the integral of the consumption density, $f(s)$, equal 1 (12). The consumer's budget constraint (13) then determines the consumption scaling factor, $\|C\|$.

Since the output of each individual finn (of measure zero on the real line) makes no significant contribution to economy-wide learning, the current behavior of any particular firm does not influence its future profitability, and hence all firms find it optimal to maximize current profits:

(15) $\underset{p(s)}{\operatorname{Max}} \pi(s)=C(s) L[p(s)-a(s)]=\|C\| L f(s)[p(s)-a(s)]$

From which it follows that the equilibrium price of each good $s$ is given by: $:^{22}$

${ }^{20}$ Given sufficient variability in goods prices. If all goods shared the same equilibrium price, the consumer would obviously choose to consume them all.

${ }^{21}$ Appendix 1 explores the technical aspects of the consumer's optimization problem.

${ }^{22}$ Since the individual firm is of insignificant measure on the real line, $\partial \lambda / \partial p(s)=\partial\|C\| / \partial p(s)=\partial p(Z) / \partial p(s)=0$. 


$$
\text { (16) } p(s)=\frac{p(Z)+a(s)}{2}
$$

The instantaneous equilibrium is illustrated in figure 1(a). Consumer's consume a range of goods $\tau=T-Z$ and $\eta=N-T$ on either side of $T$. Given the unitary income elasticities, $\tau$ is invariant with respect to $T$ and $E$ and is determined by $\eta$ alone. ${ }^{23}$ An increase in $\eta$ leads to substitution away from goods below $\mathrm{T}(d \tau / d \eta<0)$, with the total variety $(\tau+\eta)$ of goods consumed increasing. Not surprisingly, the consumption scaling factor $C C$ is linear in $E / \bar{a} e^{-T}$. Finally, firms charge a price equal to the average of their marginal cost of production and the price of the limit consumption good, good $\mathrm{Z}$.

In drawing figure 1(a), I have assumed that $T$ is sufficiently large so that good 0 is no longer consumed. I have also assumed that $\eta$ is not too large, in the following sense: If $\eta$ is larger than some critical value $\eta^{*}$, then, as illustrated in figure $1(b)$, consumption is symmetric around $\mathrm{T}$ and the most recently invented goods, in $\left[T+\eta^{*}, N\right]$, are not consumed. Although the blueprints to produce these goods exist, their costs of production have not yet fallen to a level where they can be profitably marketed. This is a case where basic research has outstripped economy-wide learning, producing inventions which are not immediately profitable.

As can be seen from figure 1, the position of a firm relative to the society's current level of learning (T) affects that firm's markup. Firms which are either near obsolescence (near Z) or on the cutting edge of the society's technology (near $N$ ) have lower markups than firms which have just attained maturity (i.e. are near T). This result is due to the fact that the society's cost structure, normalized to units of syımmetric utility, is $v$ shaped. If, instead, utility adjusted costs

${ }^{23}$ See appendix 1. In Young (1991), where demand is not unit elastic, the variety of goods consumed increases with expenditure or technical progress. 
FIGURE 1: STATIC EQUILIBRIUM

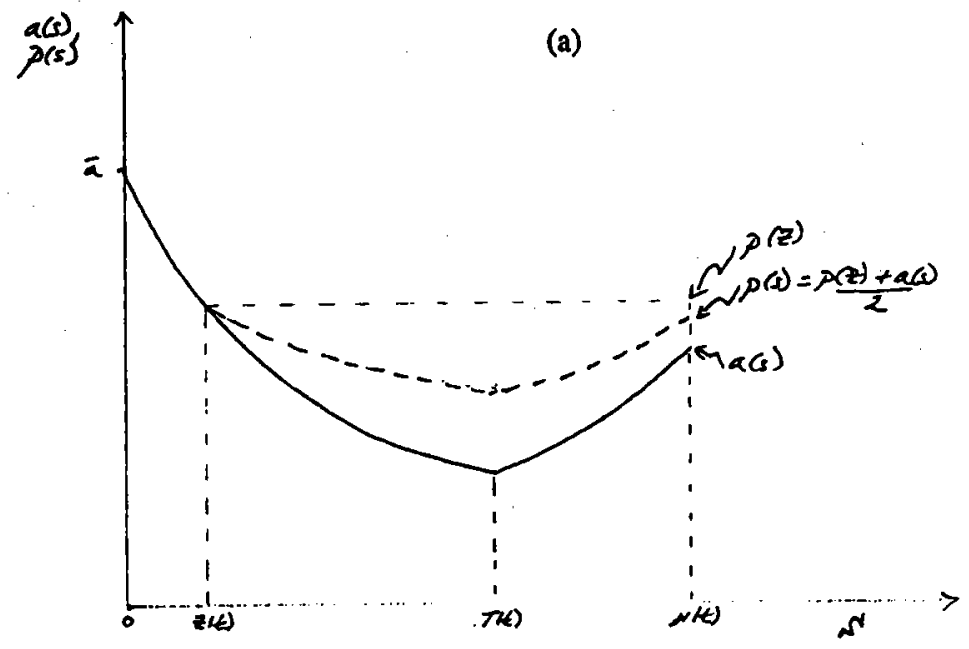

(b)

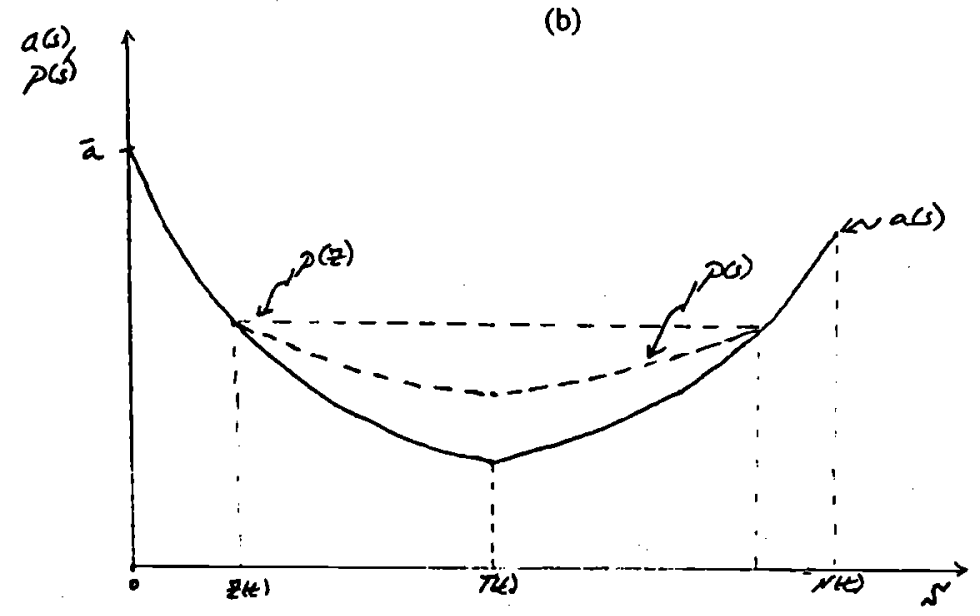


of production were monotonically decreasing, ${ }^{2 \mu}$ then markups would be monotonically increasing in the technical sophistication of the industry. An allowance for a finite patent length as well as durability in consumption would both tend to introduce some monotonicity in markups in favour of recent inventions.

Given the pattern of consumer expenditure determined by (14) and (16), it is possible to compute the (consumer) price of a unit of instantaneous utility, $U(\{C(., t)\}):^{25}$

(17) $P_{U}=\bar{a} e^{-T}\left[(\tau+\eta) e^{\tau}+2-e^{\tau}-e^{\eta}\right] / 2$

Whereas the actual (labour) cost of producing this unit of utility is:

(18) $M C_{U}=\frac{\bar{a} e^{-\tau}\left(2+e^{2 \tau}-4 e^{\tau}+2 e^{\eta} e^{\tau}-e^{2 \eta}\right)\left(e^{\tau}(\tau+\eta)+2-e^{\tau}-e^{\eta}\right)}{e^{2 \tau}(2 \tau+2 \eta)+2-e^{2 \tau}-e^{2 \eta}}$

Thus, overall, in this monopolistically competitive setting there is a markup (relative to costs) of: $:^{26}$

$$
\text { (19) } \frac{P_{U}}{M C_{U}}=\frac{e^{2 \tau}(\tau+\eta)+1-e^{2 \tau} / 2-e^{2 \eta} / 2}{2+e^{2 \tau}-4 e^{\tau}+2 e^{\eta} e^{\tau}-e^{2 \eta}}=m(\eta)
$$

It is easily verified that this markup is decreasing in $\eta_{.}{ }^{27}$ not only because, as discussed above, firms on the technological edge have lower markups, but also because an increase in $\eta$ implies an equalization of the structure of prices facing consumers, thereby increasing the elasticity of

\footnotetext{
${ }^{24}$ For example, let $a(s, t)=\bar{a} e^{-s} \forall s \in[0, T]$ and $a(s, t)=\bar{a} e^{-T} e^{\left.x_{s}-T\right)} \forall s \in[T, N]$, where $-1<\gamma<0$.

${ }^{25}$ Once again, see appendix 1 for computational details.

${ }^{26}$ If $\eta \geq \eta^{\circ}$, substitute $\eta^{\circ}$ for $\tau$ and $\eta$ in equations (17)-(19).

${ }^{27}$ For $\eta<\eta^{*}$. For $\eta \geq \eta^{*}$, it is invariant with respect to $\eta$.
} 
demand, and driving down the markups of all firms in the economy. This result would hold even if the markup were monotonically increasing in $s$. The very fact that firms to the right of $T$ are above their lower bound on unit costs, whilst firms to the left of $T$ are on their lower bound, implies that an increase in $\eta$ will tend to equalize the cost and price structure of the economy, providing consumers with more symmetric altematives, and thereby increasing the elasticity of demand.

Finally, labour market equilibrium requires that the demand for labour in manufacturing $\left(L_{N}\right)$ and research $\left(L_{R}\right)$ equal the total supply:

(20). $L_{M}+L_{R}=L$

Not surprisingly, the amount of labour in final goods production depends upon consumer expenditure and the economy-wide markup over costs:

(21) $L_{M}=\left(\frac{E L}{P_{U}}\right) M C_{U}=\frac{E L}{m(\eta)}$

with the distribution of that labour between learning and non-learning industries determined by $\eta$ :

(22) $L_{L B D}=L_{M} h(\eta) \quad L_{N L B D}=L_{M}[1-h(\eta)]$

where: $:^{29}$

(23) $h(\eta)=\frac{2 e^{\tau} e^{\eta}-2 e^{\tau}-e^{2 n}+1}{2+e^{2 \eta}-4 e^{\tau}+2 e^{n} e^{\tau}-e^{2 \eta}} \leq 1 / 2 \quad h^{\prime}(\eta)>0$

${ }^{28}$ This is due to the fact that no good is essential in consumption.

${ }^{29} h(\eta)=h\left(\eta^{\circ}\right)=1 / 2$ when $\eta \geq \eta^{\circ}$, since, in that case, demand is distributed symmetrically across learning and non-learning industries (examine figure $1(b)$ ). 


\section{INTERTEMPORAL EQUILIBRIUM}

Having derived the equilibrium price of a unit of utility, we can consider the consumer's dynamic optimization problem as one of picking an expenditure plan, $E(t)$, so as to maximize:

(24) $P=\int_{1}^{\infty} e^{-\alpha(v-1)}\left\{\log [E(v)]-\log \left[P_{U}(v)\right]\right\} d v$

subject to the intertemporal budget constraint (5) earlier above. This leads to the familiar optimality condition for the time path of expenditure $E(t)$ :

$$
\text { (25) } \frac{\dot{E}(t)}{E(t)}=\dot{R}(t)-\rho
$$

Turning to the behavior of firms, let $\mathrm{V}(\mathrm{s}, \mathrm{t})$ equal the asset market value of holding the patent to good $s$ at time $t:$

(26) $V(s, t)=\int_{1}^{-} e^{-R(v)+R(t)} \pi(s, v) d v$

where $\pi(s, t)$ denotes the profits of firm $s$ at time t. Differentiating (26) with respect to time yields an expression for the interest rate:

(27) $\dot{R}(t)=\frac{\dot{V}(s, t)}{V(s, t)}+\frac{\pi(s, t)}{V(s, t)} \quad \forall s$

which simply states that, in this deterministic environment, asset market equilibrium requires that the return to holding the patent to any good $s$ (profits plus patent value appreciation) must equal 
the risk free rate of retum. Free entry into the inventive process will ensure that the present discounted value of the profits of firm $\mathrm{N}(\mathrm{t})$ will be less than or equal to the cost of invention: ${ }^{30}$

$$
a_{R} \geq V(N(t), t)=\int_{1}^{-} e^{-R(v)+R(t)} \pi(N(t), v) d v \quad(=\text { if } \dot{N}(t)>0)
$$

Assuming that $\dot{N}(t)>0$ and thus (28) holds with equality, we can differentiate to derive an expression for $\dot{R}(t)$ as a function of easily determinable values: ${ }^{31,32}$

$$
\text { (29) } \begin{aligned}
\dot{R}(t) & =\frac{\pi(N(t), t)-\dot{N}(t)\left[\int_{1}^{-} e^{-R(v)+R(t)} \pi_{1}(N(t), v) d v\right]}{a_{R}} \\
& =\frac{\pi(N(t), t)-\dot{N}(t) V_{1}(N(t), t)}{a_{R}}
\end{aligned}
$$

Figure 2 helps explain equilibrium condition (29). At any point in time, the value of each firm depends upon its position along the real line. Finns $s \leq Z(t)$ have a value of zero, since, as demand has moved to the right, they will never again eam any profits. ${ }^{33}$ Free entry into the inventive process ensures that $V(N(t), t)=a_{k}$. Thus, we know there exists a differentiable ${ }^{24}$ curve

${ }^{30}$ Consider, by devoting labour $l_{\mathrm{R}}$ to invention for an infinitesimally small period of time dt, a firm can, at cost $I_{R} d t$, acquire patents to goods in $\left(N(t), N(t)+l_{R} d v / a_{R}\right]$, which, again for infinitesimally small $d t$, have value $V(N(t), t) l_{k} d U a_{k}$. With free entry, profits in the process of invention are driven to zero, and hence, $a_{k}=V(N(t), t)$.

${ }^{31}$ If $\dot{N}=0$, then $L_{R}=0$ and the equilibrium interest rate can be determined by differentiating (21) with respect to time and applying (25). tion.

${ }^{32}$ The subscripted 1 denotes the derivative with respect to the first argument of the func-

${ }^{33}$ Increases in either $\mathrm{T}$ or $\mathrm{N}$ move $\mathrm{Z}$ to the right. Hence, once a firm $\mathrm{s}$ has become $\mathrm{Z}(\mathrm{t})$, there will never again be any demand for its product.

${ }^{34}$ Examine (26), (15), (16) and (14). 
FIGURE 2: MARKET VALUE OF FIRM S

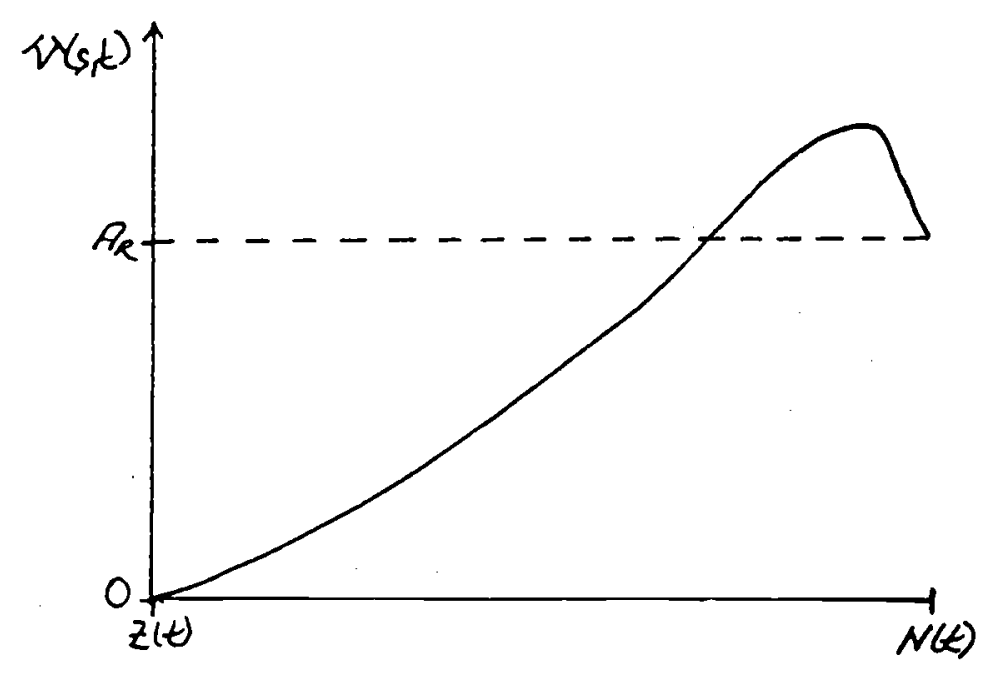


describing $V(s, t)$ linking the coordinates $(Z(t), 0)$ and $\left(N(t), a_{k}\right)$, as drawn in the figure. This curve need not be monotonic, nor is it stationary through time. Comparing (27) and (29), we see that we need to show that $V_{2}(N(t), t)=-\dot{N}(t) V_{t}(N(t), t)$. At time $t$, the value of firm $N(t), V(N(t), t)$, equals $a_{k}$. However, at that sane time $t$, firm $N(t)$ is, as a result of invention, being pushed to the left in figure 2 (since some other firm is becoming $N(t+d t)$ ). The rate of change of the value of firm $N(t), V_{2}(N(t), t)$, depends upon the derivative of the $V(s, t)$ function at the point $N(t)$, $\mathrm{V}_{\mathrm{l}}(\mathrm{N}(\mathrm{t}), \mathrm{t})$, times the rate at which firm $\mathrm{N}(\mathrm{t})$ is being pushed to the left, $\dot{N}(t)$. Hence, $V_{2}(N(t), t)=-\dot{N}(t) V_{1}(N(t), t)$, which explains (29).

To summarize, consumers, maximizing current utility subject to current expenditure, choose a distribution of expenditure across goods which depends only on $\eta(t)=N(t)-T(t)$, as illustrated in figure 1 , with the density of expenditure given by (14). Maximizing intertemporal utility, consumers find it optimal to set the growth rate of expenditure equal to the interest rate minus their rate of time discount (25). Existing firms, competing monopolistically, find it optimal to set their current price as the average of the price of the limit consumption good, $Z(t)$, and their costs of production (16). Free entry into invention, combined with asset market equilibrium, detennines the interest rate as a function of the profits of the most advanced firm $(N(t))$ and the rate of change of the value of that firm (29). The current level of consumer expenditure, as well as the economy's current structure (as given by $\eta(t)$ ), determines the amount of labour allocated to industries in which learning continues and industries in which learning has been exhausted (21-22). Labour market clearing requires that this labour, plus the labour allocated to research, equal the total labour force (20). Given these relations, the intertemporal equilibrium then consists of dynamic paths for $T(t), \eta(t)$ and $E(t)$ which satisfy equations (2), (3) and (5). 


\section{STEADY STATE BEHAVIOR}

In the steady state, $\mathrm{E}$ and $\eta$ must be constant. This implies that the real rate of interest $(\dot{R})$ equals the rate of time discount $(\rho)$, and that the rate of invention $(\dot{N})$ equals the rate of learning $(\dot{T})$. Using the labour market clearing condition (20) and the free entry condition (28) this determines $E$ and $\eta$ as functions of the parameters $L, \psi, a_{R}$ and $\rho$. With a constant steady state level of expenditure, $E$, and a steadily declining price of a unit of $\mathrm{U}(\mathrm{C}(\mathrm{.}))$, $P_{U}=\bar{a} e^{-T}\left[(\tau+\eta) e^{\tau}+2-e^{\tau}-e^{\eta}\right] / 2$, the proportional rate of growth of $U$ is equal to the equilibrium rate of learning (and invention), $\dot{T}=\dot{N}$, which I shall call g. ${ }^{35}$

Before turning to a general analysis of the steady state, it is useful to examine two extreme types of equilibria. This model, as in the invention models of Romer (1990) and Grossman and Helpman (1989), allows for a stagnant steady state, with zero growth. In that case, $\eta=\dot{T}=\dot{N}=0$, and all of the firms in (Z,T earn an infinitely lived stream of constant profits. This will constitute an equilibrium if and only if the present discounted value of the profits of firm $T$ are less than or equal to the cost of invention, ${ }^{36}$ which leads to the following condition:

(30) $a_{R} \geq L / \rho$

In this model, $\mathrm{L}$ represents the effective size of the market over which firms can recoup the costs of invention. Condition (30) states that if this market is small enough, or the cost of invention $\left(a_{k}\right)$ or the steady state rate of interest $(\rho)$ are large enough, the economy will stagnate. ${ }^{37}$ Inter-

${ }^{35}$ Since instantaneous utility is actually the $\log$ of $U$, for $\rho>0$ total intertemporal utility will always be bounded, regardless of how large $\mathrm{g}$ is.

${ }^{36}$ If they were greater than the cost of invention, then economic actors would find it profitable to invent products infinitesimally to the right of $T$.

${ }^{37}$ One can interpret (30) as saying that the annuity value of the cost of invention $\left(\rho a_{R}\right)$ must be greater than or equal to the instantaneous profits of firm $T$ (which just so happen to equal $L$ ). 
estingly, the rate of labour learning, $\psi$, has no effect on the existence of this equilibrium; for there must be at least some minimal level of invention for learning to occur and have an impact on growth. This contrasts with the typical leaming by doing model, in which there is always some growth (even at small scales of production) and in which the rate of growth is always strictly increasing in the rate of leaming. Thus, for small market sizes this model behaves exactly like an endogenous growth model based solely upon invention (with no modelling of learning).

For $L, \rho$, and $a_{R}$ such that (30) does not hold, the steady state growth rate is positive, with $\eta>0$. An increase in $L / a_{R}$ raises the relative profitability of invention, leading to an endogenous increase in $\eta$, which lowers markups, squeezes profitability and reestablishes equilibrium. For large enough $L$ or small enough $a_{R}$, the steady state equilibrium $\eta$ exceeds $\eta^{*}$ (recall figure $1 b$ ). In this case, potential profits are so large (relative to the cost of invention) that fims find it optimal to invent products before these are even marketable, holding the patents until aggregate production experience brings their costs of production down to acceptable levels. The rate of growth is then given by:

$$
\text { (31) } g=\frac{\psi L}{2+\psi a_{R}}
$$

Although both the cost of invention and the leaming parameter influence the rate of growth, it is apparent that, in this equilibrium, the growth rate is independent of the overall process of invention. For example, a subsidy to invention (lowering the effective cost to inventors) would only increase $\eta$, without influencing the steady state growth rate in any way. ${ }^{38}$ Thus, for large values of the scale parameter, $\mathrm{L}$, this model behaves like a simple learning by doing model with a con-

\footnotetext{
${ }^{30}$ In fact, during the transition dynamics, in which $\eta$ increases, it would actually lower the
} growth rate by drawing labour out of the learning sector. 
stant learning parameter ${ }^{39}$ leading to unbounded growth, in which one can, for all intents and purposes, ignore the process of invention.

These two extreme equilibria, inventive stagnation and learning constrained growth, illustrate the mechanisms at work in this model. Although there are two activities necessary for sustained growth, leaming and invention, only the latter is compensated (by the award of the infinitely lived patent). For small markets the reward given to entrepreneurs is too small to induce them to undertake inventive activities. It is easily shown that for $L=\rho a_{R}$ a small subsidy to invention, leading to positive inventive activity, would lead to an improvement in social welfare. For large markets, the reward given to inventors is too large, leading to the production of inventions which are (temporarily) of no social benefit. Given a positive rate of time discount, the society would like to see resources temporarily withdrawn from invention and allocated to the uncompensated growth activity (learning). Thus, a tax on inventive activities would improve social welfare. Perhaps the most obvious lesson of this model is that when two activities are jointly necessary for growth, but only one is compensated, then, despite the fact that the compensated activity generates positive externalities which are not captured by private actors, it is still possible that, from a social point of view, too many resources are devoted to that activity.

Outside of these two types of equilibria, the steady state growth rate is positive, with $\eta^{*}>\eta>0$. The determination of the equilibrium growth rate can be analyzed with some simple graphical tools. One can think of this economy as having two sectors, a final (consumption) goods sector and an invention (growth) goods sector. Using the equation:

$(P P F) \quad L_{M}+g a_{R}=L$

\footnotetext{
${ }^{39}$ Equal to $\psi /\left(2+\psi a_{R}\right)$.
} 
one can draw a production possibilities frontier illustrating the potential tradeoffs between the size of the final goods sector (as measured by $L_{M}$ ) and the rate of invention, $g$ (figure 3a).

Clearly, a rise in $\mathrm{L}$ shifts the curve out, whilst an increase in $\mathrm{a}_{\mathrm{R}}$ rotates it clockwise.

In the steady state the rate of leaming must equal the rate of invention. This "balanced growth" relation can be written as:

(BG) $\psi h(\eta) L_{M}=g$

which, for given $\eta$, can be drawn as a ray emanating from the origin. As $\eta$ increases, a greater proportion of any manufacturing labour force is allocated to learning industries $\left(h^{\prime}>0\right)$, and thus the curve rotates clockwise, reaching the limiting locus $\psi L_{M} / 2=g$ for $\eta \geq \eta^{*}$. An increase in $\psi$ rotates the BG curve clockwise.

Finally, free entry into invention defines a factor market equilibrium relation, which states that the retum on devoting a unit of labour to invention, i.e. $V(N(t), t) / a_{R}$, must be less than or equal to the real return to labour in manufacturing, i.e. 1 :

(FME) $\quad 1 \geq V(N(t), t) / a_{k}$

It is easily shown that $V(N(t), t)$ depends upon the steady state size of the final goods market, as measured by $L_{M}$, and lifetime profits per unit of market size, which depend upon $\eta, \rho$ and $g:^{40}$

(32) $V(N(t), t)=L_{M} T(\eta, \rho, g)$

A rise in $L_{M}$, for given $\eta, \rho$ and $g$, will raise the value of firm $N(t)$. The partial effect of an increase in the steady state rate of invention and leaming, $g$, is more ambiguous. With a more rapid rate of learning, firms find that the society's production basket is moving to the right more rapidly, thus the firm transits more quickly from being firm $N(t)$ at time $t$, to being firm $T\left(t^{\prime}\right)$ at time $t^{\prime}$, to being firm $Z\left(t^{*}\right)$ at time $t^{*}$. As a finn goes from being $N(t)$ to $T\left(t^{\prime}\right)$ its profitability rises

\footnotetext{
${ }^{40}$ For details, see appendix 2.
} 
FIGURE 3: GRAPHICAL DETERMINATION OF THE STEADY STATE

(a)

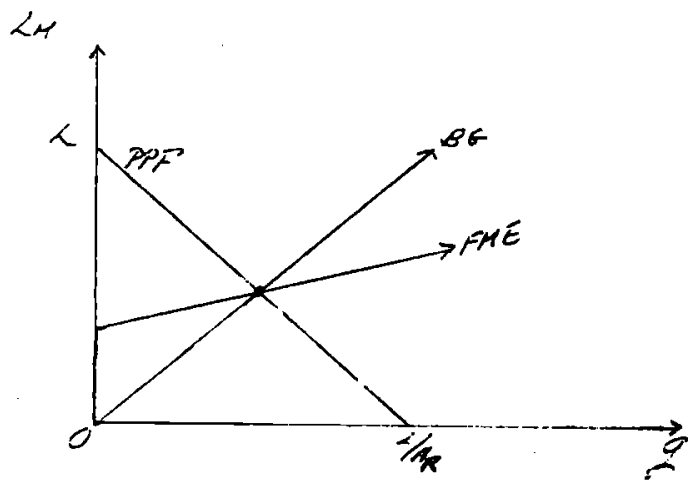

(b)
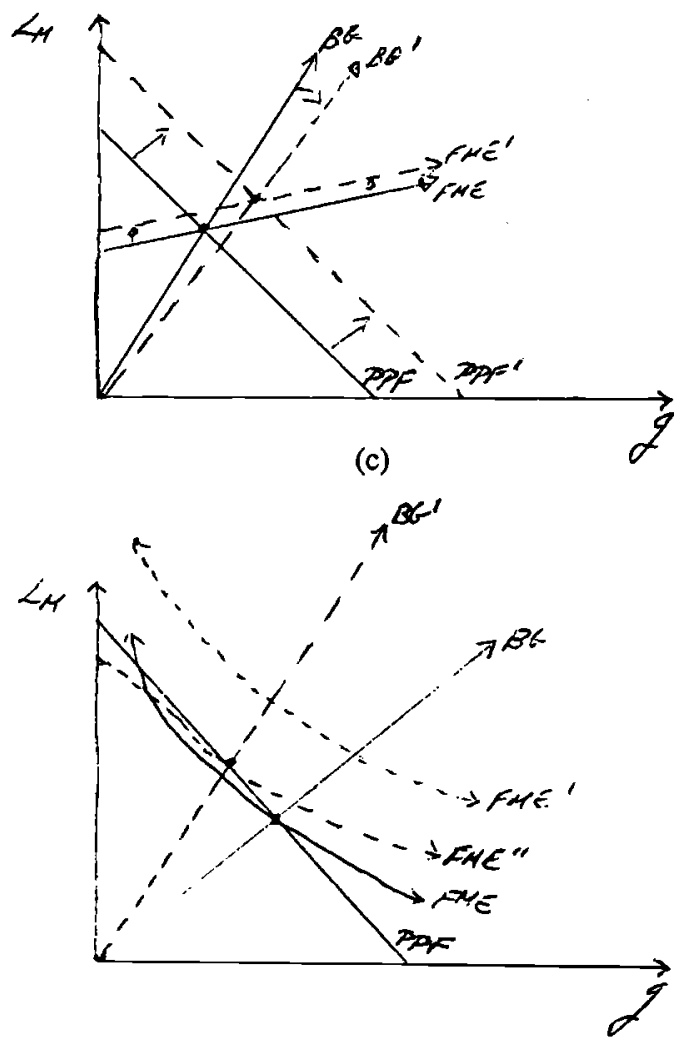
(see figure 1 earlier), but its profitability falls as it transits from $T\left(t^{\prime}\right)$ to $Z\left(t^{*}\right)$. In addition, although a more rapid rate of aggregate learning puts a firm in a more desirable state $\left(T\left(t^{\prime}\right)\right)$ at an earlier date, the more rapid rate of transit also ensures that the firm will spend less time in each such state and ultimately move on to less desirable states. Whether the net effect is positive or negative depends upon the distance between $\mathrm{N}$ and $\mathrm{T}(\eta)$, as well as the discount rate $\rho .^{41}$ Thus, in ( $\left.g, \mathrm{~L}_{M}\right)$ space the factor market equilibrium relation may slope upwards or downwards. ${ }^{42}$ An increase in either $\eta, \rho$ or $a_{k}$ will, for any given market size and rate of growth, lower the relative profitability of invention, shifting the entire FME curve up.

The steady state size of the final goods market $L_{M}$, rate of learning and invention $g$, and level of $\eta$ are determined by the joint intersection of these three curves. ${ }^{43,4}$ For example, consider an expansion in the resource base, $\mathrm{L}$ (figure $3 \mathrm{~b}$ ). At the original growth rate $\mathrm{g}$, invention is now more profitable, leading to a surge in inventive activity which outpaces the rate of learning, increasing $\eta$. As $\eta$ rises, the balanced growth equation rotates down (more of any given manufacturing labour force is allocated to learning industries) and the factor market equilibrium rela-

${ }^{41}$ For example, for a discount rate of zero, the net effect is always negative, since there is no benefit to arriving at a more favourable state earlier in time, but the higher rate of transit ensures that the time spent in each state is shorter. Similarly, as $\eta$ goes to zero, the net effect becomes negative, since, along [Z,T], the firm finds itself moving more rapidly into less profitable states. For large $\rho$ and large $\eta$, however, it can be shown that the net effect is unambigously positive.

${ }^{42}$ Although the FME curve is always flatter than the BG curve, it may, when negatively sloped, be either more or less steep than the PPF.

${ }^{43}$ An additional appendix, available upon request from the author, proves the existence of a unique solution, as well as showing that the FME curve is flatter than the BG curve and that the FME curve may be steeper than the PPF.

${ }^{4} \mathrm{I}$ have focused my analysis on $L_{M}$, rather than $E$, since the steady state value of the latter depends upon the overall markup and is therefore harder to interpret. Using (21), $L_{M}$ and $\eta$ jointly determine the steady state value of $E$. 
tion shifts upwards (lower retum to invention requiring an increase in market size), establishing a new equilbrium with, relative to the original steady state, increased levels of $L_{M}, g$ and $\eta$.

Altematively, an increase in $\rho$ will shift the FME curve up (figure 3c). As invention becomes less profitable, the rate of learning will begin to outstrip the rate of invention, leading to a drop in $\eta$. Consequently, the FME curve will shift back down, and the BG curve rotate up, reestablishing a steady state equilibrium with a larger manufacturing labour force $\left(\mathrm{L}_{M}\right)$ and lower levels of $\eta$ and $g$.

Using similar graphical analyses, it is possible to derive the following results: ${ }^{45}$

$$
\begin{array}{llll}
\partial g / \partial L>0 & \partial g / \partial a_{r}<0 & \partial g / \partial \psi>0 & \partial g / \partial \rho<0 \\
\partial L_{M} / \partial L>0 & \partial L_{M} / \partial a_{R}{ }_{s}^{2} 0^{46} & \partial L_{M} / \partial \psi<0 & \partial L_{M} / \partial \rho>0 \\
\partial \eta / \partial L>0 & \partial \eta / \partial a_{R}<0 & \partial \eta / \partial \psi_{\leq}^{2} 0^{47} & \partial \eta / \partial \rho<0
\end{array}
$$

${ }^{45}$ The graphical analysis becomes somewhat more complicated when the downward sloping FME curve is steeper than the PPF. In that case, an increase in $\eta$ moves both the FME and $B G$ curves to the right. It can be shown, however, that the FME curve always moves further along the PPF than the BG curve. Thus, for example, in the case of an increase in $\rho$ analyzed in figure 3c, if the FME curve were steeper than the PPF, then the initial upward shift in the FME curve would put its intersection with the PPF to the right of that of the BG curve. A fall in $\eta$, however, would move the FME curve to the left (along the PPF) faster than it would the BG curve, reestablishing a three way intersection at a lower level of $\eta$.

${ }^{46}$ The ambiguous effect of $a_{R}$ on $L_{M}$ follows from the fact that whereas when $\eta$ is near zero an increase in $a_{R}$ increases $L_{M}$ (by shutting down all invention), when $\eta>\eta^{*}$ an increase in $a_{R}$ lowers $\mathrm{L}_{M}$ (by drawing labour out of manufacturing into invention).

${ }^{47} \mathrm{~A}$ rise in $\psi$ increases the effective labour force, releasing labour from manufacturing for use in research. Whereas the contraction in $\mathrm{L}_{M}$ lowers firm profitability, implying the need to lower $\eta$, the partial effect of an increase in $g$ is ambiguous. If the FME curve is steeper than the PPF (implying that the partial effect of $g$ is strongly positive), the net effect of increasing $g$ and lowering $L_{M}$ is to raise firm profitability, necessitating a rise in $\eta$. Hence the ambiguous effect of an increase in $\psi$ on $\eta$. 
The results are not surprising: economies endowed with more effective units of the factor used intensively in the growth process grow faster. Consequently, increases in $\mathrm{L}$ or reductions in $a_{\mathbf{R}}$ increase the steady state growth rate. Similarly, an increase in $\psi$ raises the rate of learning, increasing the effective resource base available for use in balanced growth.

Finally, it is interesting to note that this model has implications for the relationship between growth rates and the share of rents in national income. Presumably, most economies face the same underlying technical opportunities, i.e. have similar $a_{R}$ 's and $\psi$ 's, but vary in their resource base, $L$. An increase in $L$ leads to a steady state rise in $\eta$, lowering the economy wide markup. Consequently, economies which grow faster will tend to have lower markups and, thus, a lower share of rents in national income. ${ }^{48}$. It is a common belief that in slow growth economies a larger proportion of income is derived from rents, with the usual explanation focusing on the perceived detrimental effects of rent seeking on growth. The model of this paper suggests that the direction of causality might in fact be the reverse. In economies with low growth rates, holders of privilege reap large rents because there are few emerging competitors. If the economy were growing faster, then, even though each new entrant also acquired privilege, the intensified competition could lower the overall proportion of rents in national income. If one wants to argue that rent seeking reduces growth rates, the argument should perhaps rest, not on the detrimental

\footnotetext{
${ }^{48}$ Total profit income (TPI) equals total sales times profits per sale: $T P I=\frac{E L}{P_{U}}\left(P_{U}-M C_{U}\right)=E L \frac{m(\eta)-1}{m(\eta)}$
}

Using the PPF and BG relations, as well as (21), one can eliminate E and solve for TPI in the steady state:

$$
T P I_{s s}=L\left\{\frac{m(\eta)-1}{1+\psi a_{R} h(\eta)}\right\}
$$

The share of rents in national income equals TPL/(L+TPI), which is clearly homogeneous of degree zero in L. As $m^{\prime}(\eta)<0$ and $h^{\prime}(\eta)>0$, it follows that an increase in $\eta$ brought about by an increase in $\mathrm{L}$ will lower the share of rents in national income. 
effects of rent seeking per se, but rather on the attempts by existing rentiers to bar other claimants to government decreed privilege. Thus, rent seeking by economic actors in a fairly open political system, such as that of the United States, need not have detrimental effects on growth, and might, in fact, encourage growth by allowing innovators to reap rewards greater than those that could be achieved under a free market system. ${ }^{49}$

${ }^{49}$ The positive welfare effects of granting innovators temporary monopolies are cleanly illustrated in Krugman (1988). 


\section{CONCLUSION}

If one truly believed most simple unbounded learning by doing models, one would be at a loss to explain the prolonged periods of stagnation experienced by all economies prior to the modern era. Instead, history seems to suggest that in any given environment there really is only a finite amount of knowledge that can be acquired serendipitously, without conscious effort or cost. Thus, a realistic model of growth must address the incentives for the conscious and costly invention of new goods and production processes. At the same time, leaming by doing appears to be a genuine empirical phenomenon which not only leads to enormous improvements of existing technologies but also, one would inagine, must influence the incentives for further invention. Thus, there seems to be a dynamic interaction between leaming and invention which is worth exploring both theoretically and empirically.

To this end, this paper has presented a formal model of the interaction between invention and learning. Learning depends upon invention in that learning is viewed as the serendipitous exploration of the finite productive potential of invented technologies. At the same time, the profitability of costly invention is dependent upon leaming in that costs of production depend upon the society's aggregate historical leaming experience. The resulting model is a true hybrid. With small markets, the profitability of invention is low, and hence the rate of invention becomes the constraining factor in growth, with the learning parameter having little or no effect. With large markets, invention is extremely profitable and the constraining influence becomes the rate of learning, which in turn depends upon the pattern of consumer demand.

These results are suggestive of the types of issues the different types of endogenous growth models might most appropriately address. For the analysis of the early stages of the industrial revolution, models of invention, with their emphasis on minimum market size and the incentives for costly invention, would seem to be most appropriate. In the case of the analysis of the inter- 
action of modern trading economies, although it is undoubtably true that the generation and international transmission of inventions is of substantial import, given the far less constraining influence of market size it would also seem that the insights into the detrimental effects of static comparative advantage provided by rather simple unbounded learning by doing models might not be without merit. 


\section{APPENDIX 1: CONSUMER'S OPTIMIZATION PROBLEM}

This appendix presents some of the mathematical details of the consumer's optimization problem and the instantaneous equilibrium. Combining (11)-(13), one can form the Lagrangian:

$$
\text { (1.1) } \mathcal{L}=\int_{0}^{N(1)}\|C\| g(f(s)) d s+\lambda\left[E-\int_{0}^{N(t)}\|C\| \rho(s) f(s) d s\right]+\zeta\left[\|C\|-\int_{0}^{N(1)}\|C\| f(s) d s\right]
$$

The conditions necessary and sufficient for $\mathrm{f}(),. \zeta, \lambda$, and $|C|$ to maximize this Lagrangian are: ${ }^{30}$

(1.2) $g^{\prime}(f(s)) \leq \zeta+\lambda p(s) \quad(=$ if $f(s)>0)$

(1.3) $1=\int_{0}^{N(t)} f(s) d s$

(1.4) $E=\int_{0}^{N(1)}\|C\| p(s) f(s) d s$

(1.5) $\lambda E=\int_{0}^{N(1)}\|C\| g(f(s)) d s$

Since as $p(s) \rightarrow p(Z)$ from below, $f(s) \rightarrow 0$, it follows, from (1.2), that $\zeta=1-\lambda_{p}(Z)$.

Substituting back into (1.2) yields equation (14) in the text, which holds for all goods s such that $p(s) \leq p(Z)$.

Substituting (14) and (16) from the text into (1.3)-(1.5), and integrating:

$$
\begin{aligned}
& (1.3)^{\prime} \quad 1=\left(\lambda \bar{a} e^{-\tau} / 2\right)\left[(\tau+\eta) e^{\tau}+2-e^{\tau}-e^{\eta}\right] \\
& (1.4)^{\prime} \quad E=\left(\|C\| \lambda \bar{a}^{2} e^{-2 \tau} / 4\right)\left[e^{2 \tau}(\tau+\eta)+1-e^{2 \tau} / 2-e^{2 \eta} / 2\right]
\end{aligned}
$$

\footnotetext{
${ }^{50}$ Concavity of $g($.$) ensures concavity of the integrand in f(s)$. Thus the inequality constrained Euler equation (1.2) is both necessary and sufficient for a path $f(s)$ to maximize (1.1). Taking the optimal $\mathrm{f}(\mathrm{s})$ as given, since the Lagrangian is negative semidefinite in $\mid C \|, \zeta$ and $\lambda$, the first order conditions (1.3)-(1.5) are necessary and sufficient for an optimum; where (1) I treat the problem as one of unconstrained optimization, since (1.4) will ensure that $\|C\|$ is nonnegative; and (2) the envelope theorem ensures that the partial of $f(s)$ with respect to $|C|, \zeta$ and $\lambda$ does not appear in these first order conditions.
} 


$$
(1.5)^{\prime} \quad \lambda E=\|C\|\left[1-\lambda \bar{a} e^{-T} e^{s} / 2\right]+\lambda E / 2
$$

where $\tau=T-Z$ and $\eta=N-T$. These equations allow for solutions for $\lambda,|C|$ and $\tau$ as functions of the state variables $E, \eta$, and $\bar{a} e^{-T}$. $\tau$ is determined as an implicit function of $\eta$ alone by:

(1.6) $\Phi(\tau, \eta)=2\left[(\tau+\eta) e^{\tau}+2-e^{\tau}-e^{\eta}\right]\left[(\tau+\eta) e^{\tau}+2-2 e^{\tau}-e^{\eta}\right]-e^{2 \tau}(\tau+\eta)-1+e^{2 \tau} / 2+e^{2 \eta} / 2=0$ It is easily seen that for $\eta<\eta^{\circ}, \eta^{\circ} \ni \Phi\left(\eta^{\circ}, \eta^{\circ}\right)=0, \Phi$ determines a unique $\tau>\eta^{*}>\eta$, with $d \tau / d \eta<0$. For $\eta \geq \eta^{*}, \tau$ simply equals $\eta^{*}$ and (1.6) no longer applies. ${ }^{31}|C|$ and $\lambda$ are given by: $:^{32}$

(1.7) $|C|=\frac{2 E\left[(\tau+\eta) e^{\tau}+2-e^{\tau}-e^{\eta}\right]}{\bar{a} e^{-\tau}\left[e^{2 \tau}(\tau+\eta)+1-e^{2 \tau} / 2-e^{2 \eta} / 2\right]}$

(1.8) $\lambda=\left\{\left(a e^{-\tau} / 2\right)\left[(\tau+\eta) e^{\tau}+2-e^{\tau}-e^{\eta}\right]\right\}^{-1}$

Examining (1.1), it is readily apparent that $\lambda^{-1}$ is the price of a unit of utility at the consumer optimum, which is the origin of equation (17) in the text. Define $\|C\|_{1}$ as the $|C|$ necessary to enjoy one unit of utility at the consumer optimum. This is easily determined using $U\{C()\}=.\lambda E=1$ and $(1.5)^{\prime}$. Then, the total labour used in producing a unit of $\mathrm{U}$ equals $\|C\|_{1} \int_{0}^{N} f(s) a(s) d s$, which, after some substitution using (14), (16), (1.6) and (1.8), yields (18) in the text.

${ }^{31}$ That is, in equations (1.3)'-(1.5)' one substitutes $\eta^{*}$ for $\tau$ and $\eta$.

${ }^{52}$ For $\eta \geq \eta^{\circ}$, substitute $\eta^{\circ}$ for $\tau$ and $\eta$. 


\section{APPENDIX 2: $V(N(t), t)=L_{M} T(\eta, \rho, g)$}

This appendix derives the explicit formula for $V(N(t), t)$. Using (14)-(16) we know that the flow of profits of any firm s such that $a(s) \leq a(Z)$ equals:

(2.1) $\pi(s)=\frac{|C| L \lambda[a(Z)-a(s)]^{2}}{4}$

Substituting for $|C|$ and $\lambda$, using (1.7) and (1.8), yields:

(2.2) $\pi(s)=\frac{E L\left[e^{\tau}-e^{s-\tau}\right]^{2}}{e^{2 \pi}(\tau+\eta)+1-e^{2 \tau} / 2-e^{2 \pi} / 2} \quad$ if $N \geq s \geq T$

$$
=\frac{E L\left[e^{\tau}-e^{T-s}\right]^{2}}{e^{2 \tau}(\tau+\eta)+1-e^{2 \tau} / 2-e^{2 \eta} / 2} \quad \text { if } Z \leq s \leq T
$$

For a firm $s$ invented at time 0 (i.e. $s=\mathrm{N}(0)), s-T=\eta-g t$ until such time as $t=\eta / g$, after which $T-s=g t-\eta$, until such time as $t=\eta / g+\tau / g$; after which the firm earns zero profits.

The steady state value of firm $N(t)$ equals the present discounted value of its future profits:

(2.3) $\quad V(N(t), t)=V(N(0), 0)=\int_{0}^{-} e^{-p t} \pi(N(0), t) d t$

Or:

(2.4) $V(N(t), t)=\frac{E L\left\{\int_{0}^{W_{g}}\left(e^{\tau}-e^{\eta-s^{\prime}}\right)^{2} e^{-p t} d t+\int_{\gamma_{g}}^{\eta_{g}+v_{g}}\left(e^{\tau}-e^{g^{t}-\eta}\right)^{2} e^{-p t} d t\right\}}{e^{2 \tau}(\tau+\eta)+1-e^{2 \tau} / 2-e^{2 \eta} / 2}$

Since $L_{M}=E L / g(\eta)$, it follows that $V(N(t), t)=L_{M} T(\eta, \rho, g)$, where:

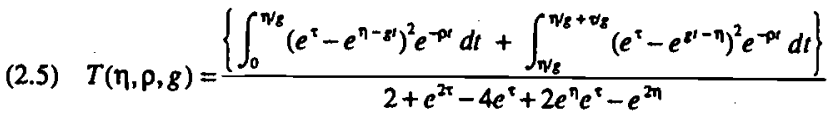


In the preceeding I have assumed that $\eta \leq \eta^{*}$. If $\eta>\eta^{*}$, then: $:^{3 !}$

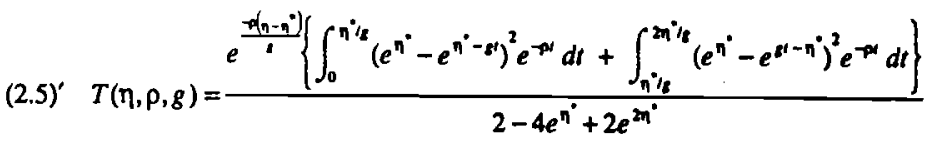

${ }^{\text {st }} e^{-p\left(\eta-\eta^{n}\right)}$ represents the discount term for the time the firm must wait until it begins to earn profits. 


\section{BIBLIOGRAPHY}

Alchian, Armen. "Reliability of Progress Curves in Airframe Production." Econometrica 31, No. 4 (October 1963): 679-693.

Arrow, Kenneth J. "The Economic limplications of Learning by Doing." Review of Economic Studies 29 (1962): 155-173.

Asher, Harold. "Cost-Quantity Relationslyips in the Airframe Industry." Rand Corporation, R-291, July 1, 1956.

Baloff, Nicholas. "Startups in Machine-Intensive Production Systems." Lournal of Industrial Engineering 14, No. 1 (January 1966): 25-32.

Bardhan, Pranab K. Economic Growth Development and Foreign Trade. New York: WileyInterscience, 1970.

Car, Gardner W. "Peacetime Cost Estimating Requires New Leaming Curves." Aviation 45, No. 4 (April 1946): 76-77.

Conway, R.W. and Schultz, Andrew Jr. "The Manufacturing Progress Function." Journal of Industrial Engineering 10, No. 1 (Jan-Feb. 1959): 39-54.

Enos, John L. "A Measure of the Rate of Technological Progress in the Petroleum Refining Industry." Joumal of Industrial Economics 6, No. 3 (June 1958): 180-197.

Fudenberg, Drew and Tirole, Jean. "Learning-by-Doing and Market Performance." Bell Journal of Economics. Vol. 14, No. 2, Autumn 1983: 522-530.

Grossman, Gene M. and Helpnan, Elluanan. "Comparative Advantage and Long-Run Growth." American Economic Review 80, No. 4 (September 1990): 796-815.

and __ "Quality Laddcrs in the Theory of Growth." Manuscript. Princeton N.J.: Princeton University, August 1989.

Hirsch, Werner Z. "Firm Progress Ratios." Econometrica 24, No.2 (April 1956): 136-143.

Jaffe, Adam B. "Technological Opportunity and Spillovers of R\&D: Evidence from Firns' Patents, Profits and Market Value." American Economic Review 76, No. 5 (December 1986): 984-1001.

Krugman, Paul. "Endogenous Innovation, Intemational Trade, and Growth." Manuscript. Canbridge: Massacliusetts Institute of Technology, 1988.

Krugman, Paul. "The Narrow Moving Band, the Dutch Disease, and the Competitive Consequences of Mrs. Thatcher: Notes on Trade in the Presence of Dynamic Scale Economies." Journal of Developmens Economics 27 (1987): 41-55. 
Levhari, David and Sheshinski, Eytan. "Experience and Productivity in the Israel Diamond Industry." Econometrica 41, No. 2 (March 1973): 239-253.

Lieberman, Marvin B. "The Learning Curve and Pricing in the Chemical Processing Industries." Rand Journal of Economics 15, No. 2 (Summer 1984): 213-228.

Lucas, Robert E., Jr. "On the Mechanics of Economic Development." Lournal of Monetary Economics 22 (July 1988).

Mak, James and Walton, Gary M. "Steamboats and the Great Productivity Surge in River Transportation." Lournal of Economic History 32, No. 3 (September 1972): 619-640.

Rivera-Batiz, Luis A. and Romer, Paul A. "Intemational Change with Endogenous Technical Change." Working Paper. University of Chicago and University of Califormia at Berkeley. October 1989.

Romer, Paul M. "Endogenous Technological Change." Јournal of Dolitical Economy 98, No. 5, pt. 2 (October 1990): S71-S102.

Rosenberg. Nathan. Inside the Black Box: Technologv and Economics. Cambridge: Cambridge University Press, 1982.

Segerstrom, Paul S.; Anant, T.C.A.; and Dinopoulos, Elias. "A Schumpeterian Model of the Product Life Cycle." American Economic Review. Vol. 80, No. 5, December 1990: 1077-1091.

Spence, Michael A. "The Learning Curve and Competition." Bell Journal of Economics. Vol. 12, No. 1, Spring 1981: 49-70.

Stokey, Nancy L. "The Dynamics of Industrywide Learning." In Heller, Walter P. et al eds. Equilibrium Analysis: Essays in honor of Kenneth J. Amow. Cambridge: Cambridge University Press, 1986.

"Human Capital, Product Quality, and Growth." Manuscript: Evanston: Northwestem University, 1990.

"Learning by Doing and the Introduction of New Goods." Joumal of Political Economy 1988, Vol. 96, no. 4: 701-717.

Wan, Henry Y. Jr. "Trade, Development and Inventions - The Evolutionary Path." Manuscript. Ithaca, N.Y.: Comell Univ., July 1975.

Wright, T.P. "Factors Affecting the Cost of Airplanes." Journal of the Aeronautical Sciences 3, No.4 (February 1936): 122-128.

Young, Alwyn. "Learning by Doing and the Dynamic Effects of International Trade." Quarterly Joumal of Economics, forthcoming May 1991. 